\title{
Knowledge Gaps in the Pharmacokinetics of Therapeutic Proteins in Pediatric Patients
}

\author{
Bernd Meibohm * \\ Department of Pharmaceutical Sciences, College of Pharmacy, The University of Tennessee Health Science Center, Memphis, \\ TN, United States
}

Therapeutic proteins such as monoclonal antibodies and their derivatives, fusions proteins, hormone analogs and enzymes for replacement therapy are an ever-growing mainstay in our pharmacopoeia. While a growing number of these medications are developed for and used in younger and younger pediatric patients, knowledge gaps in the basic understanding of the molecular and physiologic processes governing the disposition of these compounds in the human body and their modulation by age and childhood development are a hindrance to the effective and timely development and clinical use of these compounds, especially in very young pediatric patient populations. This is particularly the case for the widespread lack of information on the ontogeny and ageassociated expression and function of receptor systems that are involved in the molecular processes driving the pharmacokinetics of these compounds. This article briefly highlights

\section{OPEN ACCESS}

Edited by:

Catherine M. T. Sherwin,

Wright State University, United States

Reviewed by:

Honghui Zhou,

Janssen Research and Development (United States), United States

*Correspondence: Bernd Meibohm bmeibohm@uthsc.edu

Specialty section: This article was submitted to Obstetric and Pediatric Pharmacology, a section of the journal

Frontiers in Pharmacology

Received: 31 December 2021

Accepted: 24 January 2022

Published: 10 February 2022

Citation:

Meibohm B (2022) Knowledge Gaps in the Pharmacokinetics of Therapeutic

Proteins in Pediatric Patients.

Front. Pharmacol. 13:847021.

doi: 10.3389/fphar.2022.847021 three receptor systems as examples, the neonatal Fc receptor, the asialoglycoprotein receptor, and the mannose receptor. It furthermore provides suggestions on how these gaps should be addressed and prioritized to provide the field of pediatric clinical pharmacology the urgently needed tools for a more effective development and clinical utilization of this important class of drugs with rapidly evolving importance as cornerstone in pediatric pharmacotherapy.

Keywords: pediatrics, therapeutic proteins, pharmacokinetics, pediatric extrapolation, ontogeny, neonatal Fc receptor, mannose receptor, asialoglycoprotein receptor

\section{INTRODUCTION}

Over the past 25 years, therapeutic proteins such as monoclonal antibodies (mAbs) and their derivatives, fusions proteins, hormone analogs and enzymes for replacement therapy have gained major roles in the armamentarium to treat numerous conditions and diseases (Crommelin et al., 2019). More recently, constructs that are the result of advanced protein engineering such as bispecifics and similar innovative molecules have been added to this group of molecules and are receiving major attention in drug development programs (Rathi and Meibohm, 2015; Brinkmann and Kontermann, 2017). While these protein-based medications are typically first developed and approved for adult patient populations, extensions of regulatory approval for use in pediatric populations is frequently pursued after initial market introduction (Zhang et al., 2015; Temrikar et al., 2020). These efforts have been further spurred and formalized by regulatory incentives and regulatory requirements that have been established over the past 3 decades in Europe and North America (Zisowsky et al., 2010; Zhang et al., 2015). In this context, there is an ever growing need to 
establish dosage regimens and dosing recommendations that address the specific needs of different age groups of pediatric patients to ensure a safe and effective pharmacotherapy in these patient populations (Xu et al., 2013; Malik et al., 2021).

While pediatric dosing may be affected by differences in pharmacokinetic as well as pharmacodynamic processes but also differences in disease etiology and progression, particular interest has often been directed towards pharmacokinetic differences. This is based on the notion that full and partial extrapolation approaches of efficacy from adults to children frequently rely on exposure-matching where dosing regimens of the drug in question in different pediatric populations are selected in such a way that they achieve drug exposures in the pediatric patients "similar" to those having shown to be efficacious and safe in adults (Mulugeta et al., 2016). This approach of course relies on the assumption that the course of the disease and the response to the drug are sufficiently similar between adults and the considered pediatric population, a prerequisite that needs to be supported by adequate data.

\section{KEY MECHANISMS OF DRUG DISPOSITION PROCESSES FOR THERAPEUTIC PROTEINS}

The pharmacokinetic processes of distribution and elimination of therapeutic proteins are governed by combinations of physicochemical, physiologic and receptor-mediated processes and have been reviewed in detail elsewhere (Tang et al., 2004; Mould and Meibohm, 2016; Ryman and Meibohm, 2017; Meibohm, 2019). In brief, distribution is largely determined by molecule size and charge. Large therapeutic proteins such as mAbs with a molecular weight of $150 \mathrm{kDa}$ are largely confined to the vascular space with only limited distribution into the interstitial space of extravascular organs and tissues. Distribution for these molecules is largely driven by convective extravasation that is, determined by the number and size of pores between endothelial cells lining the blood and lymphatic vessels and pressure gradients between hydrostatic and colloid osmotic pressure in vascular, interstitial and lymphatic spaces and capillaries.

Elimination processes can broadly be distinguished into unspecific proteolytic degradation that can either be receptormediated or non-receptor-mediated (Meibohm, 2019). Nonreceptor-mediated processes are usually initiated by pinocytosis, a fluid-phase endocytotic cellular uptake of the therapeutic protein molecule followed by intracellular lysosomal degradation to small peptides and amino acids. This degradation process is performed by phagocytic cells of the reticuloendothelial system as well as endothelial cells lining blood and lymph capillaries. Organs with major capillary beds such as muscle, skin and to lesser degree the intestine as well as organs with high number of phagocytic cells are thus major contributors to this nonspecific proteolytic degradation (Eigenmann et al., 2017). In case of receptor-mediated proteolysis, the intracellular uptake may be mediated by membrane-standing promiscuous receptor systems, for example, the LDL-receptor, or sugar-recognizing receptors such as the mannose receptor. Usually, receptor-mediated uptake processes are substantially faster and more efficient than pinocytosis, and proteins using these pathways are more rapidly eliminated. In the specific case where the membrane receptor that facilitates the intracellular uptake is the pharmacologic target, one refers to target-mediated elimination. Due to the usually high binding affinity of the therapeutic protein for its pharmacologic target, the targetmediated elimination process is usually substantially faster than the elimination processes relying on pinocytosis or "unspecific" receptor-mediated endocytosis (Tang et al., 2004). For mAbs and antibody-derivatives, interaction with immunoglobulin-specific receptors such as the neonatal Fcreceptor $(\mathrm{FcRn})$ and $\mathrm{Fc} \gamma$ receptors may also affect the clearance of these therapeutic proteins. Interaction with FcRn in the acidified lysosome after intracellular uptake may prevent IgG molecules and thus mAbs from proteolytic degradation, thereby leading to an increased residence time and thus decreased clearance of these molecules in the systemic circulation (Ryman and Meibohm, 2017). Interaction between $\mathrm{mAbs}$ and $\mathrm{Fc} \gamma$-receptors expressed on immune cells, while highly relevant for processing and removal of immune complexes, may constitute additional elimination pathways, although their overall contribution seems to be limited for the majority of mAbs (Thomas and Balthasar, 2019). For small therapeutic proteins below the glomerular filtration cutoff of approximately $60 \mathrm{kDa}$, proteolytic degradation in proximal tubular cells after glomerular filtration in the kidneys may also contribute to their clearance (Meibohm and Zhou, 2012).

\section{DIFFERENCES IN THERAPEUTIC PROTEIN DISPOSITION BETWEEN CHILDREN AND ADULTS AND RELATED KNOWLEDGE GAPS}

Pediatric extrapolation efforts to establish dosing regimens for therapeutic proteins are hampered by a lack of a comprehensive understanding of the differences in drug distribution and elimination mechanisms between children and adults, particularly young pediatric patients such as full term and premature neonates and infants, i.e., in the range younger than 1 year of age. While many disposition processes based on physicochemical and physiologic processes are reasonably well understood, those related to receptor-mediated processes remain in many instances unclear or elusive. In more general terms, sizerelated differences between children and adults have relatively well been characterized, while knowledge on pediatric maturation-related differences remains spotty.

The distribution processes of most therapeutic proteins, as described in the previous section, are largely driven by conserved physicochemical processes together with physiologic differences between adults and different pediatric age groups and can thus usually be well predicted for pediatric populations. Therefore, allometric scaling approaches accounting for body size 
differences between children and adults usually characterize the distribution of therapeutic proteins well. Only for very young pediatric patients such as newborns and infants, further differences may need to be considered. These include the wellknown higher total and extracellular tissue water content, larger capillary beds and thus capillary surface area per tissue volume, and higher perfusion rates (Friis-Hansen, 1983; Malik and Edginton, 2018). All these processes together would be expected to result in faster extravasation of therapeutic proteins, lower concentration differences between the vascular and the extravascular space, and overall larger extravascular distribution volumes per volume unit of tissue (Temrikar et al., 2020). While an allometric exponent of 1 has widely been used to scale distribution volumes between children and adults based on body weight (Meibohm et al., 2005), more recent analyses considering a diverse set of protein-based therapeutics suggest that an exponent of 0.8 might be more appropriate (Malik et al., 2021).

Similar to distribution volumes, clearance values for nonreceptor-mediated proteolytic degradation processes of therapeutic proteins in children can also relatively well be derived from adult values based on allometric scaling with allometric exponents of 0.75 or 0.85 accounting solely for body size-based differences between children and adults (Malik et al., 2021). Only for children younger than 1 year of age, maturation-related differences also have to be considered. For example, young infants, newborns and particularly low-birth weight infants have been reported to exhibit a 2-3 times higher lysosomal protein turnover normalized for body weight (Beaufrere, 1994), which would be expected to affect unspecific proteolytic degradation and result in an increased protein clearance (Temrikar et al., 2020).

For receptor-mediated elimination processes, however, the available knowledgebase on age- and maturation-related differences between children and adults is very scarce. For FcRn, for example, data have been limited to rodent studies. While messenger RNA (mRNA) expression of the $a$-chain of FcRn in rats suggested an age-associated increase (Tian et al., 2014), more recent results on age-associated expression at the protein level in mice suggest no relevant differences in expression from newborn through juvenile animals to adults in skin and spleen tissues (Limothai, 2015), which may be interpreted as more definitive due to the often limited mRNA-to-functional protein correlation for many endogenous proteins including FcRn (Li and Balthasar, 2018; Temrikar et al., 2020). There are currently no human data yet available on the ontogeny of FcRn, especially in very young pediatric patients. A more likely age-associated effect on FcRn recycling of mAbs and their derivatives are the well documented substantially lower reference values for endogenous IgG subclasses in infants compared to older children and adults (Plebani et al., 1989) that would be expected to lead to less endogenous competition for FcRn and thus a more efficient recycling process with potentially reduced clearance for protein molecules interacting with FcRn (Temrikar et al., 2020).

An example for a promiscuous membrane receptor facilitating the uptake of therapeutic proteins for subsequent lysosomal degradation is the asialoglycoprotein receptor (ASGPR) (Stockert, 1995). It is expressed on hepatocytes and facilitates the uptake of proteins that carry a glycan chain with a terminal galactose or galactose derivative. Examples are erythropoietin, reteplase, lanoteplase and clotting factor VIII (Lunghi et al., 2021). ASGPR has also been implicated in the glycoform selective clearance of therapeutic proteins with complex $\mathrm{N}$ - or O-linked glycosylation structures (Jones et al., 2007; Stefanich et al., 2008). More recently, ASGPR has also been utilized to facilitate hepatic targeting of $\mathrm{N}$-acetylgalactosamine-conjugated RNA interference therapeutics (Li et al., 2021). Data on ASGPR expression and activity in children is very limited. While ASGPR has been detected in human fetal liver (Yoshida et al., 1999), agerelated expression levels are limited to mice where activity increased postpartum and reached adult levels after 5 days (Collins et al., 1984). Additional knowledge has been inferred by physiologic pharmacokinetic modelling of pharmacokinetic data for known ASGPR substrates from different species (Poulin, 2011).

Similar to ASGPR, the mannose receptor is a highly effective endocytic receptor that is expressed on selected populations of macrophages and dendritic cells, and that recognizes glycoproteins with mannosylated glycan chains (MartinezPomares, 2012). High-mannose glycoforms of mAbs have increased clearance compared to mAbs with other glycans due to interaction with the mannose receptor (Falck et al., 2021). The age-associated expression of the mannose receptor is largely unknown. In mice, the mannose receptor was first detected on macrophages on day 10 in the embryonic stage and persisted postnatally thereafter (Takahashi et al., 1998). This may imply that mannose receptor activity has already reached adult levels at birth. The major role of FcRn, ASGPR, and the mannose receptor om the disposition of therapeutic proteins are summarized in Table 1.

For target-mediated drug disposition processes, data are even more scarce than for those elimination processes related to less specific receptor systems such as ASGPR or the mannose receptor. One might expect that each target has its own specific ontogeny with age- and maturation-associated differences in target receptor abundance, turnover and internalization kinetics (Temrikar et al., 2020). This becomes especially challenging when new therapeutic targets and/or novel indications are pursued. In addition, individual pediatric patients usually follow different temporal developmental trajectories that further complicate and individualize their dose requirements for a specific therapeutic protein (Barrett et al., 2012).

\section{DISCUSSION AND PERSPECTIVES}

The selection of safe and efficacious dosing regimens for drug development and applied pharmacotherapy of therapeutic proteins in pediatric patients is severely hampered by substantial knowledge gaps on the ontogeny and ageassociated expression and function of receptor systems that are involved in the molecular processes driving the pharmacokinetics of these compounds. This is particularly relevant for newborns 
TABLE 1 | Examples of receptor systems affecting the pharmacokinetics of therapeutic proteins with unknown ontogeny.

\begin{tabular}{|c|c|c|c|}
\hline Receptor system & $\begin{array}{l}\text { Tissues } \\
\text { with high expression }\end{array}$ & $\begin{array}{l}\text { Recognized } \\
\text { molecular structure }\end{array}$ & $\begin{array}{l}\text { Examples for affected } \\
\text { therapeutic proteins }\end{array}$ \\
\hline $\begin{array}{l}\text { Asialoglycoprotein } \\
\text { receptor (ASGPR) }\end{array}$ & Hepatocytes (sinusoidal surface) & $\begin{array}{l}\text { Glycan chains with terminal galactose or } \\
\mathrm{N} \text {-acetylgalactosamine residues }\end{array}$ & $\begin{array}{l}\text { Erythropoietin; FSH; clotting factors VII, VIII, IX; } \\
\text { reteplase, lanoteplase }\end{array}$ \\
\hline Mannose receptor & $\begin{array}{l}\text { Macrophages, immature dendritic cells, and } \\
\text { liver sinusoidal endothelial cells }\end{array}$ & $\begin{array}{l}\text { Glycan chains with high mannose content } \\
\text { (M5-M9) }\end{array}$ & $\begin{array}{l}\text { High mannose forms for lgG monoclonal } \\
\text { antibodies and their derivatives }\end{array}$ \\
\hline $\begin{array}{l}\text { Neonatal Fc receptor } \\
\text { (FcRn) }\end{array}$ & $\begin{array}{l}\text { Vascular endothelial cells and phagocytic cells } \\
\text { as well as other cell types, particularly in liver, } \\
\text { spleen, intestine, lungs and lymph nodes }\end{array}$ & $\begin{array}{l}\text { FcRn pH-dependent binding site on the } \\
\text { constant domain of lgG molecule and } \\
\text { albumin }\end{array}$ & $\begin{array}{l}\text { Monoclonal antibodies; antibody-derivatives } \\
\text { and fusion proteins with intact FcRn-binding site } \\
\text { on the Fc domain; albumin fusion proteins }\end{array}$ \\
\hline
\end{tabular}

and infants where differences in therapeutic protein pharmacokinetics cannot be fully explained by size differences between children and adults and where additional maturation processes need to be considered. This article briefly highlighted three receptor systems as examples, FcRn, ASGPR and the mannose receptor, but numerous others may be involved in the disposition process of specific therapeutic proteins as well. Priorities for filling these knowledge gaps should be initially directed towards those receptor systems that are more broadly relevant to the largest number of therapeutic proteins, for example, $\mathrm{FcRn}$ for all $\mathrm{mAbs}$ and $\mathrm{mAb}$ derivatives with intact FcRn binding site.

Population pharmacokinetic modeling (PopPK) and physiological pharmacokinetic modeling (PBPK) have been widely used in support of pediatric extrapolation exercises based on exposure-matching approaches for traditional small molecule drugs (Conklin et al., 2019). While PopPK is a datadriven, deductive modeling approach, PBPK can be viewed as an inductive approach based on the integrated prior knowledge of drug- and system-specific parameters and structures (Barrett et al., 2012). A recent analysis of FDA approval data for the 20 monoclonal antibodies and Fc-fusion proteins approved at the time in both adult and pediatric indications revealed that while 19 of the 20 projects included PopPK based modeling and simulation in support of the selected pediatric dosing regimens, only one of them included a PBPK approach (Liu et al., 2019). This lack of use of PBPK for therapeutic proteins in pediatric indications may partially be related to the highlighted knowledge gaps in understanding pediatric disposition of these molecules as PBPK rather than PopPK is largely dependent on an intrinsic understanding of the drug disposition mechanisms and pathways that underlie a therapeutic protein's pharmacokinetic behavior.

\section{REFERENCES}

Barrett, J. S., Della Casa Alberighi, O., Läer, S., and Meibohm, B. (2012). Physiologically Based Pharmacokinetic (PBPK) Modeling in Children. Clin. Pharmacol. Ther. 92, 40-49. doi:10.1038/clpt.2012.64

Beaufrère, B. (1994). Protein Turnover in Low-Birth-Weight (LBW) Infants. Acta Paediatr. Suppl. 405, 86-92. doi:10.1111/j.1651-2227.1994. tb13404.x

Brinkmann, U., and Kontermann, R. E. (2017). The Making of Bispecific Antibodies. MAbs 9, 182-212. doi:10.1080/19420862.2016.1268307
There have recently been elegant attempts to impute the lack of age-associated function of receptor systems such as FcRn through PBPK modeling frameworks using known PK data of endogenous and therapeutic proteins (Hardiansyah and $\mathrm{Ng}$, 2018; Pan et al., 2020). While these approaches are pragmatic in the current situation, they still cannot overcome the residual uncertainty associated with the arbitrary assignment of ageassociated disposition behavior to one unmeasured model component. This underlines the need for basic molecular pharmacology investigations in the age groups of interest to fill our existing knowledge gaps with high quality data. The gained knowledge would likely not only benefit one specific development project or compound but would likely be more broadly applicable. These opportunities to add to the collective pediatric drug disposition knowledgebase will be crucial to advance the reliability and reduce the uncertainty of pediatric extrapolation efforts (Laer et al., 2009; Temrikar et al., 2020). Only then will the currently existing uncertainties in extrapolation of therapeutic proteins to pediatric patients be overcome and a more widespread application of prospective modeling frameworks in this area be possible.

\section{DATA AVAILABILITY STATEMENT}

The original contributions presented in the study are included in the article/supplementary material, further inquiries can be directed to the corresponding author.

\section{AUTHOR CONTRIBUTIONS}

The author confirms being the sole contributor of this work and has approved it for publication.

Collins, J. C., Stockert, R. J., and Morell, A. G. (1984). Asialoglycoprotein Receptor Expression in Murine Pregnancy and Development. Hepatology 4, 80-83. doi:10.1002/hep.1840040114

Conklin, L. S., Hoffman, E. P., and Van Den Anker, J. (2019). Developmental Pharmacodynamics and Modeling in Pediatric Drug Development. J. Clin. Pharmacol. 59 (Suppl. 1), S87-S94. doi:10.1002/jcph.1482

Crommelin, D. J. A., Sindelar, R. D., and Meibohm, B. (2019). Pharmaceutical Biotechnology: Fundamentals and Applications. New York: Springer.

Eigenmann, M. J., Fronton, L., Grimm, H. P., Otteneder, M. B., and Krippendorff, B. F. (2017). Quantification of IgG Monoclonal Antibody Clearance in Tissues. MAbs 9, 1007-1015. doi:10.1080/19420862.2017.1337619 
Falck, D., Thomann, M., Lechmann, M., Koeleman, C. A. M., Malik, S., Jany, C., et al. (2021). Glycoform-resolved Pharmacokinetic Studies in a Rat Model Employing Glycoengineered Variants of a Therapeutic Monoclonal Antibody. MAbs 13, 1865596. doi:10.1080/19420862.2020.1865596

Friis-Hansen, B. (1983). Water Distribution in the Foetus and Newborn Infant. Acta Paediatr. Scand. Suppl. 305, 7-11. doi:10.1111/j.1651-2227.1983.tb09852.x

Hardiansyah, D., and Ng, C. M. (2018). Effects of the FcRn Developmental Pharmacology on the Pharmacokinetics of Therapeutic Monoclonal IgG Antibody in Pediatric Subjects Using Minimal Physiologically-Based Pharmacokinetic Modelling. MAbs 10, 1144-1156. doi:10.1080/19420862.2018.1494479

Jones, A. J., Papac, D. I., Chin, E. H., Keck, R., Baughman, S. A., Lin, Y. S., et al. (2007). Selective Clearance of Glycoforms of a Complex Glycoprotein Pharmaceutical Caused by Terminal N-Acetylglucosamine Is Similar in Humans and Cynomolgus Monkeys. Glycobiology 17, 529-540. doi:10.1093/ glycob/cwm017

Läer, S., Barrett, J. S., and Meibohm, B. (2009). The In Silico Child: Using Simulation to Guide Pediatric Drug Development and Manage Pediatric Pharmacotherapy. J. Clin. Pharmacol. 49, 889-904. doi:10.1177/ 0091270009337513

Li, J., Liu, J., Zhang, X., Clausen, V., Tran, C., Arciprete, M., et al. (2021). Nonclinical Pharmacokinetics and Absorption, Distribution, Metabolism, and Excretion of Givosiran, the First Approved N-AcetylgalactosamineConjugated RNA Interference Therapeutic. Drug Metab. Dispos 49, 572-580. doi:10.1124/dmd.121.000381

Li, T., and Balthasar, J. P. (2018). FcRn Expression in Wildtype Mice, Transgenic Mice, and in Human Tissues. Biomolecules 8, 115. doi:10.3390/biom8040115

Limothai, W. (2015). "Challenges in the Pharmacokinetics of Therapeutic Proteins," in Theses and Dissertations (ETD). Paper 396. Memphis: University of Tennessee Health Science Center. doi:10.21007/etd.cghs.2015.0184

Liu, X. I., Dallmann, A., Wang, Y. M., Green, D. J., Burnham, J. M., Chiang, B., et al. (2019). Monoclonal Antibodies and Fc-Fusion Proteins for Pediatric Use: Dosing, Immunogenicity, and Modeling and Simulation in Data Submitted to the US Food and Drug Administration. J. Clin. Pharmacol. 59, 1130-1143. doi:10.1002/jcph.1406

Lunghi, B., Morfini, M., Martinelli, N., Balestra, D., Linari, S., Frusconi, S., et al. (2021). The Asialoglycoprotein Receptor Minor Subunit Gene Contributes to Pharmacokinetics of Factor VIII Concentrates in Hemophilia A. Thromb. Haemost. doi:10.1055/a-1591-7869

Malik, P., and Edginton, A. (2018). Pediatric Physiology in Relation to the Pharmacokinetics of Monoclonal Antibodies. Expert Opin. Drug Metab. Toxicol. 14, 585-599. doi:10.1080/17425255.2018.1482278

Malik, P. R. V., Temrikar, Z. H., Chelle, P., Edginton, A. N., and Meibohm, B. (2021). Pediatric Dose Selection for Therapeutic Proteins. J. Clin. Pharmacol. 61 (Suppl. 1), S193-S206. doi:10.1002/jcph.1829

Martinez-Pomares, L. (2012). The Mannose Receptor. J. Leukoc. Biol. 92, 1177-1186. doi:10.1189/jlb.0512231

Meibohm, B., Läer, S., Panetta, J. C., and Barrett, J. S. (2005). Population Pharmacokinetic Studies in Pediatrics: Issues in Design and Analysis. AAPS J. 7, E475-E487. doi:10.1208/aapsj070248

Meibohm, B., and Zhou, H. (2012). Characterizing the Impact of Renal Impairment on the Clinical Pharmacology of Biologics. J. Clin. Pharmacol. 52, 54S-62S. doi:10.1177/0091270011413894

Meibohm, B. (2019). "Pharmacokinetics and Pharmacodynamics of Therapeutic Peptides and Proteins," in Pharmaceutical Biotechnology: Fundamentals and Applications. Editors D.J.A. Crommelin, R.D. Sindelar, and B. Meibohm (New York: Spinger), 105-137. doi:10.1007/978-3-030-00710-2_6

Mould, D. R., and Meibohm, B. (2016). Drug Development of Therapeutic Monoclonal Antibodies. BioDrugs 30, 275-293. doi:10.1007/s40259-0160181-6

Mulugeta, Y., Barrett, J. S., Nelson, R., Eshete, A. T., Mushtaq, A., Yao, L., et al. (2016). Exposure Matching for Extrapolation of Efficacy in Pediatric Drug Development. J. Clin. Pharmacol. 56, 1326-1334. doi:10.1002/jcph.744

Pan, X., Stader, F., Abduljalil, K., Gill, K. L., Johnson, T. N., Gardner, I., et al. (2020). Development and Application of a Physiologically-Based Pharmacokinetic Model to Predict the Pharmacokinetics of Therapeutic Proteins from Full-Term Neonates to Adolescents. AAPS J. 22, 76. doi:10.1208/s12248-020-00460-1
Plebani, A., Ugazio, A. G., Avanzini, M. A., Massimi, P., Zonta, L., Monafo, V., et al. (1989). Serum IgG Subclass Concentrations in Healthy Subjects at Different Age: Age normal Percentile Charts. Eur. J. Pediatr. 149, 164-167. doi:10.1007/ BF01958271

Poulin, P. (2011). A Single-Species Approach Considering Additional Physiological Information for Prediction of Hepatic Clearance of Glycoprotein Derivate Therapeutics. Clin. Pharmacokinet. 50, 665-674. doi:10.2165/11592610-000000000-00000

Rathi, C., and Meibohm, B. (2015). Clinical Pharmacology of Bispecific Antibody Constructs. J. Clin. Pharmacol. 55 (Suppl. 3), S21-S28. doi:10.1002/jcph.445

Ryman, J. T., and Meibohm, B. (2017). Pharmacokinetics of Monoclonal Antibodies. CPT Pharmacometrics Syst. Pharmacol. 6, 576-588. doi:10.1002/ psp4.12224

Stefanich, E. G., Ren, S., Danilenko, D. M., Lim, A., Song, A., Iyer, S., et al. (2008). Evidence for an Asialoglycoprotein Receptor on Nonparenchymal Cells for O-Linked Glycoproteins. J. Pharmacol. Exp. Ther. 327, 308-315. doi:10.1124/ jpet.108.142232

Stockert, R. J. (1995). The Asialoglycoprotein Receptor: Relationships between Structure, Function, and Expression. Physiol. Rev. 75, 591-609. doi:10.1152/ physrev.1995.75.3.591

Takahashi, K., Donovan, M. J., Rogers, R. A., and Ezekowitz, R. A. (1998). Distribution of Murine Mannose Receptor Expression from Early Embryogenesis through to Adulthood. Cell Tissue Res 292, 311-323. doi:10. 1007/s004410051062

Tang, L., Persky, A. M., Hochhaus, G., and Meibohm, B. (2004). Pharmacokinetic Aspects of Biotechnology Products. J. Pharm. Sci. 93, 2184-2204. doi:10.1002/ jps. 20125

Temrikar, Z. H., Suryawanshi, S., and Meibohm, B. (2020). Pharmacokinetics and Clinical Pharmacology of Monoclonal Antibodies in Pediatric Patients. Paediatr. Drugs 22, 199-216. doi:10.1007/s40272-020-00382-7

Thomas, V. A., and Balthasar, J. P. (2019). Understanding Inter-individual Variability in Monoclonal Antibody Disposition. Antibodies (Basel) 8, 56. doi:10.3390/antib8040056

Tian, Z., Sutton, B. J., and Zhang, X. (2014). Distribution of Rat Neonatal Fc Receptor in the Principal Organs of Neonatal and Pubertal Rats. J. Recept Signal. Transduct Res. 34, 137-142. doi:10.3109/10799893.2013.865745

Xu, Z., Davis, H. M., and Zhou, H. (2013). Rational Development and Utilization of Antibody-Based Therapeutic Proteins in Pediatrics. Pharmacol. Ther. 137, 225-247. doi:10.1016/j.pharmthera.2012.10.005

Yoshida, S., Furuhashi, M., and Suganuma, N. (1999). Expression of Asialoglycoprotein Receptor in Human Fetal Liver. Endocr. J. 46, 67-73. doi:10.1507/endocr. 46.67

Zhang, Y., Wei, X., Bajaj, G., Barrett, J. S., Meibohm, B., Joshi, A., et al. (2015). Challenges and Considerations for Development of Therapeutic Proteins in Pediatric Patients. J. Clin. Pharmacol. 55 (Suppl. 3), S103-S115. doi:10.1002/ jcph.382

Zisowsky, J., Krause, A., and Dingemanse, J. (2010). Drug Development for Pediatric Populations: Regulatory Aspects. Pharmaceutics 2, 364-388. doi:10. 3390/pharmaceutics2040364

Conflict of Interest: The author declares that the research was conducted in the absence of any commercial or financial relationships that could be construed as a potential conflict of interest.

Publisher's Note: All claims expressed in this article are solely those of the authors and do not necessarily represent those of their affiliated organizations, or those of the publisher, the editors and the reviewers. Any product that may be evaluated in this article, or claim that may be made by its manufacturer, is not guaranteed or endorsed by the publisher.

Copyright $\odot 2022$ Meibohm. This is an open-access article distributed under the terms of the Creative Commons Attribution License (CC BY). The use, distribution or reproduction in other forums is permitted, provided the original author $(s)$ and the copyright owner(s) are credited and that the original publication in this journal is cited, in accordance with accepted academic practice. No use, distribution or reproduction is permitted which does not comply with these terms. 